\title{
PROCESSOS EDUCATIVOS NA DISCIPLINA DE LIBRAS: REPRESENTAÇÕES SOCIAIS DE GRADUANDOS DE LETRAS DO PARFOR SOBRE A SURDEZ.
}

\author{
Waldma Maíra Menezes de Oliveira ${ }^{1}$ \\ Ivanilde Apoluceno de Oliveira ${ }^{2}$
}

\begin{abstract}
RESUMO
Este estudo apresenta duas problemáticas: que Representações Sociais os graduandos de Letras - Língua Portuguesa do PARFOR da Universidade Federal do Pará possuem sobre o Surdo? E, qual o possível efeito da disciplina de Libras na (re) construção de representações dos graduandos sobre o Surdo? Nesta investigação, realizou-se uma pesquisa de campo de abordagem qualitativa com ênfase na Teoria das Representações Sociais de característica processual de Moscovici (2009) por tratar o foco da gênese das Representações Sociais, analisando os processos de sua formação considerando a historicidade e o contexto de produção. Os entrevistados foram 03 graduandos do curso de Letras - Língua Portuguesa do Parfor/UFPA, que cursaram a disciplina Libras. Na sistematização e análise dos dados, utilizou-se a técnica da Análise de Conteúdos com ênfase na categorização. Nos resultados observou-se que os sujeitos pesquisados possuíam Representações Sociais acerca da Surdez no campo da Normalidade ressignificandoas para Diferença como Alteridade.
\end{abstract}

Palavras-Chave: Representações Sociais. Surdez. Libras. Ensino de língua Portuguesa.

\begin{abstract}
This study presents two problems: what Social Representations do the PARFOR undergraduates of Letters Portuguese Language of the Federal University of Pará have on the Deaf? And, what is the possible effect of the discipline of Brazilian Sign Language on the (re) construction of representations that undergraduates have on the Deaf? In this research, a qualitative field research was conducted with emphasis on the Theory of Social Representations of Moscovici's procedural characteristic (2009) for dealing with the focus of the genesis of Social Representations, analyzing the processes of their formation considering the historicity and the context of production. The interviewees were 03 undergraduate students of the Portuguese Language course Parfor / UFPA, who attended the Brazilian Sign Language course. In the systematization and analysis of the data, we used the technique of Content Analysis with emphasis on categorization. Analyzing the results it was observed that the subjects surveyed had Social Representations about Deafness in the field of Normality and re-signified them to Difference as Alterity.
\end{abstract}

Keywords: Social Representations. Deafness. Brazilian Sign Language. Teaching of Portuguese language.

\footnotetext{
${ }^{1}$ Professora Assistente II da Universidade Federal do Pará (UFPA). Doutoranda em Educação (PPGED/UEPA). Mestre em Educação pela Universidade do Estado do Pará (UEPA). Pesquisadora do Núcleo de Educação Popular (NEP) da UEPA. Coordenadora do Grupo de Estudos Surdos na Amazônia Tocantina - GESAT, do Coral de Libras -Mãos que Falam, da Especialização em Educação Inclusiva no Campo e da Divisão de Inclusão Educacional - DIE da Universidade Federal do Pará - Campus Cametá. CV: http://lattes.cnpq.br/9969566482712444 E-mail: waldma@ufpa.br.

${ }^{2}$ Pós-Doutora em Educação pela PUC-Rio. Doutora em Educação pela PUC-SP/UNAM/UAM-México. Professora do Programa de Pós-Graduação em Educação e Coordenadora do Núcleo de Educação Popular Paulo Freire da Universidade do Estado do Pará. CV: http://lattes.cnpq.br/6486192420682817 E-mail: nildeapoluceno@uol.com.br
} 


\section{SINALIZAÇÃO INICIAL}

O interesse pelo estudo sobre as representações sociais e a surdez ocorre a partir da disciplina - Língua Brasileira de Sinais II - ministrada à turma de Letras - Língua Portuguesa (PARFOR) na Universidade Federal do Pará, Campus Cametá. A disciplina visa proporcionar a formação inicial sobre os aspectos linguísticos da Libras e a marcação cultural, identitária e educacional da pessoa Surda.

Neste artigo partimos de duas problemáticas: quais sãos as representações sociais (RS) de graduandos de Letras - Língua Portuguesa sobre o Surdo? E, qual o possível efeito da disciplina de Libras na (re) construção de representações dos graduandos sobre o Surdo?

Objetivamos investigar as Representações Sociais de graduandos do curso de Letras Língua Portuguesa do Parfor/UFPA sobre a pessoa com Surdez e, de forma específica: analisar as imagens e os sentidos atribuídos pelos graduandos de Letras - Língua Portuguesa sobre a pessoa surda antes e depois da disciplina de Libras e elucidar as RS sobre a Surdez no âmbito da Normalidade e Diferença como alteridade.

Para atender a esses objetivos, fundamentamo-nos teoricamente em autores como: Lopes (2007); Oliveira (2015); Skliar (1998); Freire (1999, 2004) entre outros, bem como em documentos que envolvem a legislação sobre a Libras na educação de surdos, entre os quais: Brasil (2002, 2005).

O currículo do curso de Letras - Língua Portuguesa/Parfor, da Universidade Federal do Pará, apresenta 03 (três) disciplinas na área do objeto de estudo em questão, sendo elas: Libras I, Libras II e Língua Portuguesa para Surdos. A referida investigação ocorreu na disciplina Libras II ministrada no Campus Universitário do Tocantins/Cametá no período de 08 a 13 de janeiro de 2018.

O Plano Nacional de Formação de Professores da Educação Básica (PARFOR) objetiva ofertar Ensino Superior para professores atuantes na rede pública de educação básica, contemplando as exigências da Lei de Diretrizes e Bases da Educação Nacional 9.394/1996.

Segundo o Projeto Pedagógico do Curso - PPC, a disciplina Língua Brasileira de Sinais Libras II é obrigatória, correspondendo à $68 \mathrm{~h}$, com base no cumprimento legal (BRASIL, 2005).

Para Santos e Campos (2013, p. 242): "a disciplina apresenta como objetivo, inclusive no texto da Lei, uma melhor formação de professores para a atuação em salas de aula inclusivas que, possivelmente, terão a presença de alunos com os mais diversos tipos de deficiência, incluindo a surdez".

O Decreto 5.626, de 22 de dezembro de 2005, destaca a inclusão da Libras como disciplina curricular nos cursos de formação de professores. Assim, no Art. $3^{\circ}$ estabelece que: 
cursos de Fonoaudiologia, de instituições de ensino, públicas e privadas, do sistema federal de ensino e dos sistemas de ensino dos Estados, do Distrito Federal e dos Municípios.

$\S 1$ o Todos os cursos de licenciatura, nas diferentes áreas do conhecimento, o curso normal de nível médio, o curso normal superior, o curso de Pedagogia e o curso de Educação Especial são considerados cursos de formação de professores e profissionais da educação para o exercício do magistério.

$\S 20$ A Libras constituir-se-á em disciplina curricular optativa nos demais cursos de educação superior e na educação profissional, a partir de um ano da publicação deste Decreto (BRASIL, 2005).

Com a implantação da Libras nos cursos de formação de professor, espera-se que o processo de inclusão seja praticado com mais eficiência, haja vista que os futuros docentes terão conhecimento sobre a história dos surdos e aos aspectos teóricos da língua, podendo atuar positivamente na construção do conhecimento dos discente, além de facilitar a comunicação entre alunos e professores.

Com essa formação em Libras o que mudou nas representações sociais dos graduandos em Letras sobre a pessoa surda? Quais as representações sociais estes graduandos tinham antes do acesso à disciplina Libras?

Compreendemos que a formação por meio da Libras contribui para que os graduandos em letras reconstruam suas representações negativas para outras positivas, além de facilitar a comunicação entre ouvintes e surdos.

Neste artigo apresentamos inicialmente a introdução do artigo, seguida da metodologia, a sinalização da surdez, os resultados do estudo, focando os sentidos e imagens dos graduandos de Letras sobre o sujeito surdo e as ressignificações das Representações Sociais da normalidade para a diferença como alteridade, e, por fim, as considerações finais.

\section{METODOLOGIA SINALIZADA}

Nesta investigação, realizou-se uma pesquisa de campo de abordagem qualitativa. De acordo com Ludke e André (1986, p. 11), “[...] a pesquisa qualitativa tem o ambiente natural com sua fonte direta de dados e o pesquisador como seu principal instrumento".

Chizzotti $(2009$, p. 79) afirma que a abordagem qualitativa "[...] parte do fundamento de que há uma relação dinâmica entre o mundo real e o sujeito, uma interdependência viva entre o sujeito e o objeto, um vínculo indissociável entre o mundo objetivo e a subjetividade do sujeito".

Este estudo assumiu um enfoque crítico-dialético, cujas pesquisas apresentam:

Um caráter conflitivo, dinâmico e histórico da realidade. Sua postura marcadamente crítica expressa a pretensão de desvendar, mais que o "conflito das interpretações", o conflito dos interesses. Essas pesquisas manifestam um "interesse transformador" das situações ou fenômenos estudados, resgatando sua dimensão sempre histórica e desvendando suas possibilidades de mudança (GAMBOA, 1994, p. 97). 
O autor destaca que nesse tipo de pesquisa o dinamismo da práxis transformadora dos seres humanos como agentes históricos na tomada de conscientização gera a participação ativa do mesmo na organização social, política e educacional. Desse modo, a dialética trabalha "[...] com as contradições intrínsecas às ações e realizações humanas, e com o movimento perene entre parte e todo, interioridade e exterioridade dos fenômenos" (MINAYO, 2010, p. 24).

Este estudo tem por base a Teoria das Representações Sociais, com o foco na educação inclusiva e nas representações dos alunos universitários sobre a educação de surdos, isto é, na maneira em que elaboram e partilham simbologias significantes e construtivas acerca desse sujeito.

As pesquisas com a Teoria das Representações Sociais tiveram sua origem no século XX, com Moscovici (1981), e desdobram-se em quatro abordagens:

(1) processual ou sociocultural representada por Denise Jodelet, principal colaboradora de Moscovici; (2) perspectiva relacional, mais sociológica, inaugurada por Willem Doise; (3) a estrutural desenvolvida por Jean-Claude Abric com ênfase no aspecto cognitivo-estrutural; e (4) dialógica de Marková voltada para a dimensão simbólica (SOUZA, 2009, p. 161).

$\mathrm{Na}$ análise das Representações Sociais sobre educação de surdos, utilizou-se a abordagem processual, desenvolvida por Moscovici (1981; 2009) e aprofundada por Jodelet (1998; 2001). Esta abordagem visa "conhecer os processos de formação de uma representação social com o objetivo de buscar suas condições sociais de produção assim como as práticas sociais que as geram e as justificam”(ALVES-MOZZOTI; MAIA; MAGALHÃES 2010, p. 5).

A Representação Social é entendida como "[...] forma de conhecimento prático, de senso comum, que circula na sociedade. Esse conhecimento é constituído de conceitos e imagens sobre pessoas, papeis e fenômenos do cotidiano." (RANGEL, 2004, p. 66)

Os processos de formação das RS compreendem a Ancoragem ${ }^{1}$ e a Objetivação $^{2}$, os quais, por meio de uma relação dialética entre si, fomentam a construção do núcleo figurativo, que, por sua vez, é constituído de uma estrutura figurativa e simbólica (MOSCOVICI, 2009).

Os participantes da pesquisa foram 36 graduandos da Universidade Federal do Pará do Campus Cametá que fizeram a disciplina de Libras II no período de 08 a 13 de janeiro de 2018. Todavia, para este trabalho, optou-se em apresentar as imagens e sentidos de 03 (três) graduandos. Os critérios para escolha dos 03 (três) graduandos se deu: a) que já atuassem em sala de aula e b) que já tivessem trabalhado com alunos surdos. Para tanto, todos os entrevistados assinaram o Termo de Consentimento Livre e Esclarecido (TCLE) permitindo a autorização de informações para a publicação com o absoluto sigilo de sua identidade, assim os graduandos foram denominados de G1, G2 e G3.

Como metodologia para coleta das RS dos graduandos da turma, apresentou-se a seguinte estratégia: no primeiro dia de aula, foi solicitado aos alunos duas atividades para apreender suas 
representações. A primeira consistia em responder a seguinte pergunta: Quem é o surdo? Tal pergunta deveria ser respondida em apenas uma palavra e, em seguida, o graduando justificava a palavra escolhida. A segunda atividade foi proposta aos graduandos que desenhassem o surdo a partir de sua representação.

No último dia de aula, os alunos voltaram a (re) fazer as duas atividades propostas e, em seguida, compararam suas RS iniciais e finais acerca da pessoa com surdez.

Assim, as atividades foram realizadas em dois momentos: no início e no final da disciplina, realizando-se um estudo comparativo.

A técnica de elaboração do desenho foi utilizada no intuito de elucidar nos sujeitos da pesquisa conceitos, saberes e representações sobre Educação de surdos, complementando as informações obtidas nas entrevistas. Dessa maneira, a técnica do desenho aparece como base na pesquisa, pois tem o poder de evidenciar as representações obtidas pelos sujeitos que não conseguiram expressar de maneira oralizada.

O desenho se torna uma técnica indispensável a ser trabalha no enfoque das RS, já que por meio dele é possível visualizar conceitos antes não visto pelo pesquisador. Segundo Víctora et al. (2000, p. 70), a técnica de elaboração de desenhos “[...] consiste em propor aos pesquisados que representem graficamente uma determinada situação ou concepção. A partir do desenho, pesquisador e pesquisado entabulam uma discussão que se apoia nos elementos surgidos no desenho".

Na sistematização e análise dos dados, utilizou-se a técnica da Análise de Conteúdos, por se tratar de um "[...] conjunto de técnicas de análises de comunicações, que utiliza procedimentos sistemáticos e objetivos de descrição do conteúdo da mensagem" (BARDIN, 2010, p. 38). Na análise dos dados, trabalhou-se "o material acumulado, buscando destacar os principais achados da pesquisa” (LUDKE; ANDRÉ, 1986, p. 48), criando-se categorias temáticas que possibilitaram a organização do relatório da pesquisa.

De acordo com Oliveira, Oliveira e Silveira (2018) no campo das pesquisas sobre RS observa-se que os desenhos se apresentam de diferentes formas e significados. Os desenhos e os seus significados foram atrelados nas práticas educativas para pessoas surdas e na marcação da surdez.

\section{A SINALIZAÇÃO SOBRE A SURDEZ}

Para você, quem é o surdo? A pergunta pode ser respondida, automaticamente: aquele que não ouve. Tal fala se revela em uma gama de Representações Sociais, em que o não ouvir 
materializa: na falta, no dano, na ausência, na deficiência e na limitação. Desse modo, a representação se enraíza em uma concepção ouvintista.

Skliar (1998) explica que:

O ouvintismo - as representações dos ouvintes sobre a surdez e sobre os surdos - e o oralismo - a forma institucionalizada do ouvintismo - continuam sendo, ainda hoje, discursos hegemônicos em diferentes partes do mundo. Trata-se de um conjunto de representações dos ouvintes, a partir do qual o surdo está obrigado a olhar-se e a narrar-se como se fosse ouvinte. Além disso, é nesse olhar-se, e nesse narrar-se que acontecem as percepções do ser deficiente, do não ser ouvinte, percepções que legitimam as práticas terapêuticas habituais. (SKLIAR, 1998, p.15).

A concepção ouvintista foi demarcada e vivenciada, no percurso histórico da surdez, no qual "constata-se o enfoque principalmente clínico-reabilitador impôs-se durante muito tempo a quaisquer outros. De certa maneira, ele dificultou a compreensão da surdez fora de uma lógica normalizadora" (LOPES, 2007, p. 50). Em prol dessa concepção, a sociedade colocou os surdos em um mundo à parte e à margem da normalidade ouvinte. Assim, não ouvir consolidou o selo da diferença atrelado à inferioridade a esses sujeitos. Tentar romper, ressignificar e transformar tal concepção, partindo de uma ótica socioantropológica, constitui-se uma praxiologia extremamente árdua. Olhar o outro pelo prisma da diferença linguística, identitária e cultural se torna uma ação marcada pela alteridade, isto é, pelo reconhecimento da singularidade existencial de cada sujeito.

Lopes (2007) corrobora com o pensamento de Wrigley (1996) ao mencionar que, foi somente "no final do XVIII que a surdez se torna um espaço de cultura e, por isso, de interesse para uma reflexão de cunho filosófico" (LOPES, 2007, p. 47). A partir desse momento, o sujeito surdo começa a ser problematizado e conceituado por sua diferença linguística e não somente pela sua deficiência. Assim, a surdez se efetiva no lugar da diversidade, pluralidade e da cultura. Dessa forma:

Não se trata, portanto, de simplesmente negar a surdez para começarmos a fazer um discurso da diferença surda; trata-se de pensar outras formas de significação que permitem a criação de elo entre semelhantes. É preciso compreender que uma distinção cultural sempre passa pela diferença (LOPES, 2007, p. 52).

No momento em que a sociedade ancora o surdo pelo ato de não ouvir e o materializa como incapaz, impossibilita-se de observar outros elementos que constituem o sujeito surdo, como: a Língua Brasileira de Sinais, apreensão do mundo por suas experiências visuais e, que são sujeitos bilíngues etc. O selo da diferença não coloca o surdo enquanto ser superior e não aceita a marcação na inferioridade, o selo da diferença conceitua o surdo por sua singularidade, ou seja, ele não precisa da comparação com outro para ser surdo, ele é o que é por suas relações, por sua história de vida e por identificação linguística.

No posicionamento conceitual da diferença surda, Lopes (2007) argumenta: 
[...] que ela não se dá no fato de o indivíduo ser surdo, mas de este viver em comunidade e compartilhar, com seus pares, uma língua viso-gestual, uma forma de viver e de organizar o tempo e o espaço; enfim, é entre sujeitos semelhantes de uma mesma comunidade que os surdos são capazes de se colocar dentro do discurso da diferença cultural (LOPES, 2007, p. $71)$.

Outrossim, compreendemos que o surdo precisa de outro (s) Surdo (s) para se tornar Surdo. E isso ocorre através da partilha do encontro dialógico, afetivo, linguístico e identitário presente na comunidade surda. Somando-se a isso, a autora pontua que "os movimentos surdos, em prol da conquista de um espaço surdo, dos direitos de os surdos terem uma língua e de serem reconhecidos como um grupo cultural acentuaram-se no Brasil, a partir da década de 1990" (LOPES, 2007, p. 52).

É nesse bojo de luta pelo reconhecimento de sua identidade linguística que surge a Resistência Surda. Dessa forma, compreende-se que "ao se organizarem, os surdos lutam e resistem aos modelos dos saberes e à própria ordem dos discursos oficiais" (LOPES, 2007, p. 52).

\section{DADOS E RESULTADOS SINALIZADOS}

\subsection{IMAGENS E SENTIDOS SOBRE O SUJEITO SURDO}

Para iniciar as análises dos dados atrelando a imagem e o sentido dos graduandos sobre a pessoa surda, partiu-se do pensamento de Skliar (2010) ao mencionar que "a temática da surdez, na atualidade, se configura como território de representações que não podem ser facilmente delimitados ou distribuídos em 'modelos de surdez'” (SKLIAR, 2010, p. 9).

Em âmbito nacional, algumas pesquisas apontam a dificuldade da inclusão de alunos surdos, ao elucidar que a educação inclusiva desconsidera as especificidades linguísticas dos surdos, não dispondo de práticas pedagógicas que favoreçam a sua aprendizagem e não possibilitando um ambiente efetivamente bilíngue (LACERDA, 2000; LIMA, 2011; DORZIAT, 2009).

Corroborando a esse pensamento, Skliar (1998) pontua que o fracasso na educação de surdos ocorreu pela não aceitação e o não uso da Língua de Sinais na escola. Portanto, aprender Libras é processo fundamental na acessibilidade comunicacional e na inclusão educacional do surdo.

Ao iniciar a disciplina, diversos dizeres eram mencionados sobre a pessoa surda. O dizer mais eloquente foi: como vou trabalhar com uma pessoa que não pode me ouvir?

Assim, o medo do outro que não ouve e possuí uma língua diferente era a principal adversidade na prática educativa dos professores que estavam recebendo formação inicial. A 
barreira comunicacional $^{3}$ foi tratada como único elemento que impossibilitaria a inclusão do educando surdo, todavia, faz-se necessário afirmar que:

A inclusão educacional não é somente remover barreiras comunicacionais, como também, atitudinais, arquitetônicas, etc. É repensar um fazer educativo pautado na diferença como alteridade, na dialogicidade e na heterogeneidade na classe escolar (OLIVEIRA, 2015, p. 208).

O medo do diferente, neste caso, no que não ouve, está associado a ideias preconceituosas em relação a pessoa surda, como, por exemplo, que é incapaz de aprender, não tem como se comunicar, entre outras. Por isso, iniciou-se a disciplina com o intuito de ressignificar RS estigmatizadas e preconceituosas acerca do outro/surdo e mostrar a importância do conhecimento dos docentes da Libras.

O resultado desta formação está expresso nos desenhos dos sujeitos da pesquisa, evidenciando mudanças de atitudes e de comunicação entre os mesmos e o ensino com a pessoa surda, de uma visão negativa para positiva, de impossibilidade para possibilidade e de medo para desafios.

O sujeito G1 ilustrou em seu desenho que, antes da disciplina, o seu aluno surdo tentava se comunicar, mas por não saber a Língua Brasileira de Sinais a mesma se sentia perdida no caminho relacional e educacional do aluno surdo. Após a disciplina, G1 retratou em seu desenho uma conversa entre ela (professora) e o surdo (aluno) e afirmou "que a disciplina possibilitou a aprendizagem de alguns sinais" (G1, 2018). 
Figura 1: Inclusão do surdo

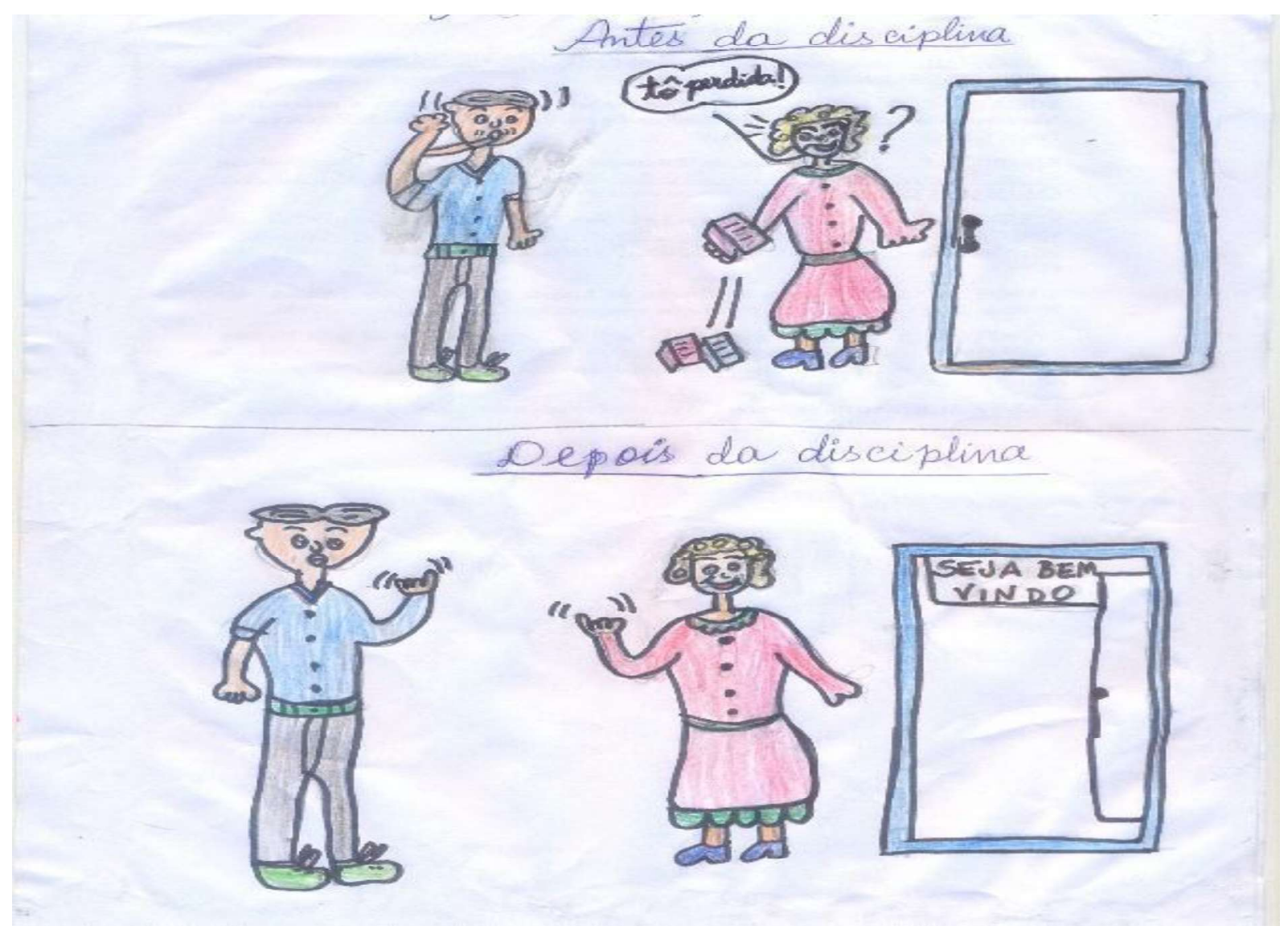

Fonte: (G1, 2018).

Observamos no desenho de G1 o semblante de dúvida da professora por não saber Libras e, posteriormente, a felicidade ao se comunicar com o aluno surdo dizendo um "oi!", e a simbologia da porta fechada/aberta.

A RS presente no desenho demarca que aceitação do outro ocorre a partir da aceitação das diferenças, neste caso, da diferença linguística. G1 compreendeu a importância e aprendeu, de acordo com sua referida fala, alguns sinais de Libras. Em prol desse posicionamento, reforçamos o dizer quando eu aceito a Língua de sinais eu aceito o surdo, posto que a língua faz parte da constituição do eu, isto é, a língua é elemento que nos constitui sujeitos sociais.

Assim, conforme a RS do desenho de G1 a porta está aberta para: relação, aceitação, aprendizagem, diálogo, afetividade e reciprocidade. Elementos esses que irão constituir uma diferença partindo da Alteridade enquanto medida conceitual, relacional e educacional no âmbito da surdez.

No desenho de G1 a Porta é demarcada como categoria de Significado. Para Oliveira, Oliveira, Silveira (2018) os desenhos ao representarem uma dada situação expressam, também, os seus significados. Assim, a porta aberta faz menção ao acesso e fechada a ausência dele. Posto que 
O significado presente em cada desenho emerge para além de um discurso, isto é, o entrevistador consegue através da fala do entrevistado e da comparação com a imagem descrever a real ação da mensagem tida. O significado no campo das imagens semióticas nas Representações Sociais está para além do tido e do dito, sendo um valor simbólico da mensagem e do desenho (OLIVEIRA, OLIVEIRA, SILVEIRA, 2018, p. 46).

G2 ratifica a imagem e o sentido sobre o sujeito surdo de G1. Em seu desenho, antes da disciplina, percebe-se o surdo sentado e isolado e depois da disciplina G2 se coloca de braços abertos para recebê-lo. De acordo com G2 "o que aprendi vai além de sinais, vai para aceitação do surdo e da sua língua".

Figura 2: Aceito o surdo e sua língua

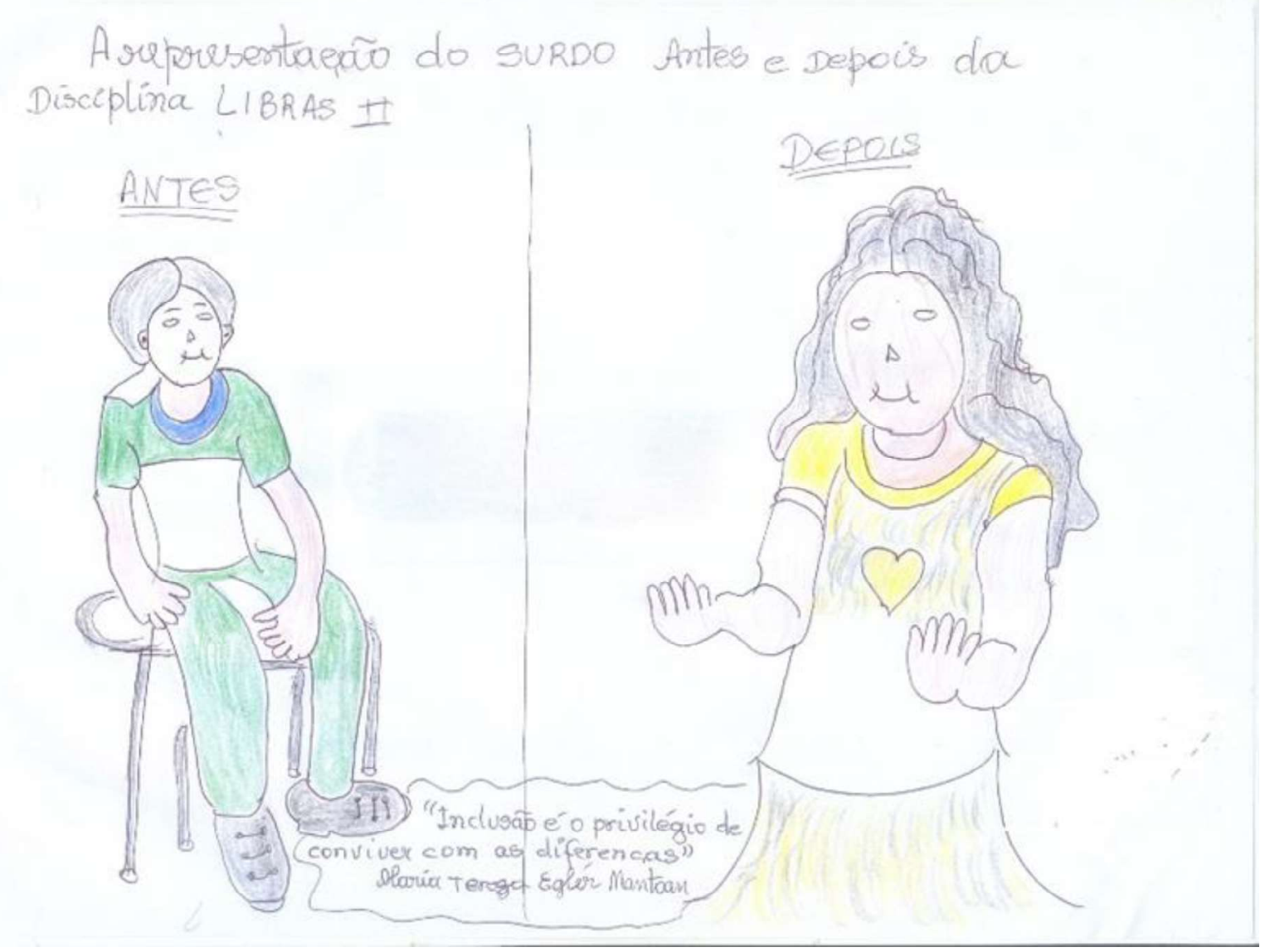

Fonte: $(\mathrm{G} 2,2018)$

Destaca-se no desenho a chamada de acolhimento à pessoa surda e a estampa do coração na roupa, demonstrando aceitação do outro, do diferente e do processo de inclusão escolar. Tais elementos são conceituados enquanto categoria de Pontos de Destaque segundo Oliveira, Oliveira, Silveira (2018), posto que exemplificam a ação do outro (professora) para com o outro diferente de si (surdo)

Entretanto, o acolhimento ao outro inclui a possibilidade de comunicar-se por meio da Libras. Lodi (2006) menciona que o surdo se torna um estrangeiro em seu próprio país, posto que a 
Libras não é compreendida e usada por todos, o que proporciona um ambiente, linguisticamente, desfavorável para sua inclusão socioeducacional.

Novamente, marca-se o posicionamento: para que ocorra inclusão deve haver aprendizagem da Libras nas escolas. Tal conceituação é referida por G1 e G2 ao ilustrarem em seus desenhos a necessidade da professora regente aprender Libras para incluir o aluno com surdez. Mas será que esse aprendizado se reduz ao professor? E os demais alunos? E os funcionários da escola? E a família?

A partir desses questionamentos é que se ilustram a necessidade de tornar o ambiente bilíngue para a efetivação da inclusão do aluno surdo. Goldfeld (1997) destaca que as dificuldades dos surdos ocorrem justamente pelo fato de a surdez impedir que estes adquiram naturalmente as línguas auditivo-orais, únicas utilizadas pela grande maioria das comunidades.

Assim, faz-se necessário uma educação bilíngue que preconize o ensino do surdo pela L1 (Libras) e, posteriormente, ensinado na Língua da comunidade ouvinte na qual está inserido, em sua modalidade escrita. De acordo com Quadros (2005), o ambiente bilíngue não é, simplesmente, o local em que duas línguas se façam presentes, isso vai:

Para além da questão da língua, portanto, o bilinguismo na educação de surdos representa questões políticas, sociais e culturais. Nesse sentido, a educação dos surdos, em uma perspectiva bilíngue, deve ter um currículo organizado em uma perspectiva visuo-espacial para garantir o acesso a todos os conteúdos escolares na própria língua das crianças, a língua de sinais brasileira é a proposição da inversão, assim está reconhecendo a diferença. A língua passa a ser, então o instrumento que traduz todas as relações e intenções do processo que se concretizam através das interações sociais (QUADROS, 2005, p. 34).

Entretanto, isso só poderá se materializar em ações inclusivas quando o reconhecimento da surdez for pautado na diferença e não na anormalidade, na patologia e no déficit, já que:

Os surdos formam uma comunidade linguística minoritária caracterizada por compartilhar uma Língua de Sinais e valores culturais, hábitos e modos de socialização próprios. A Língua de Sinais constitui o elemento identificatório dos surdos, e o fato de constituir-se em comunidade significa que compartilham e conhecem usos e normas de uso da mesma língua já que interagem cotidianamente em um processo comunicativo eficaz e eficiente. Isto é, desenvolveram as competências linguística e comunicativa - e cognitiva- por meio do uso da Língua de Sinais própria de cada comunidade de surdos (SKLIAR, 1997, p. 143).

Infelizmente, esse compartilhar ainda está sendo feito, em sua maioria, entre surdo e surdo, e surdo e intérprete educacional, com os demais sujeitos esse ato se restringe na língua, nos valores culturais e hábitos. Todavia, quando a comunidade escolar aprende a Língua Brasileira de Sinais o encontro com o outro/surdo se dá face-a-face marcado na autenticidade e nas relações sociais e educacionais.

G3 ilustra em seu desenho, antes da disciplina, o monolíngue e, posteriormente, um ambiente bilíngue, e demarca em sua fala a seguinte representação "antes só ensinava o alfabeto na 
Língua Portuguesa aos meus alunos, agora sei que a Língua dele (surdo) deve estar presente aqui, pois todos devem saber para comunicar com ele" (G3, 2018).

Figura 3: Caminhos para inclusão

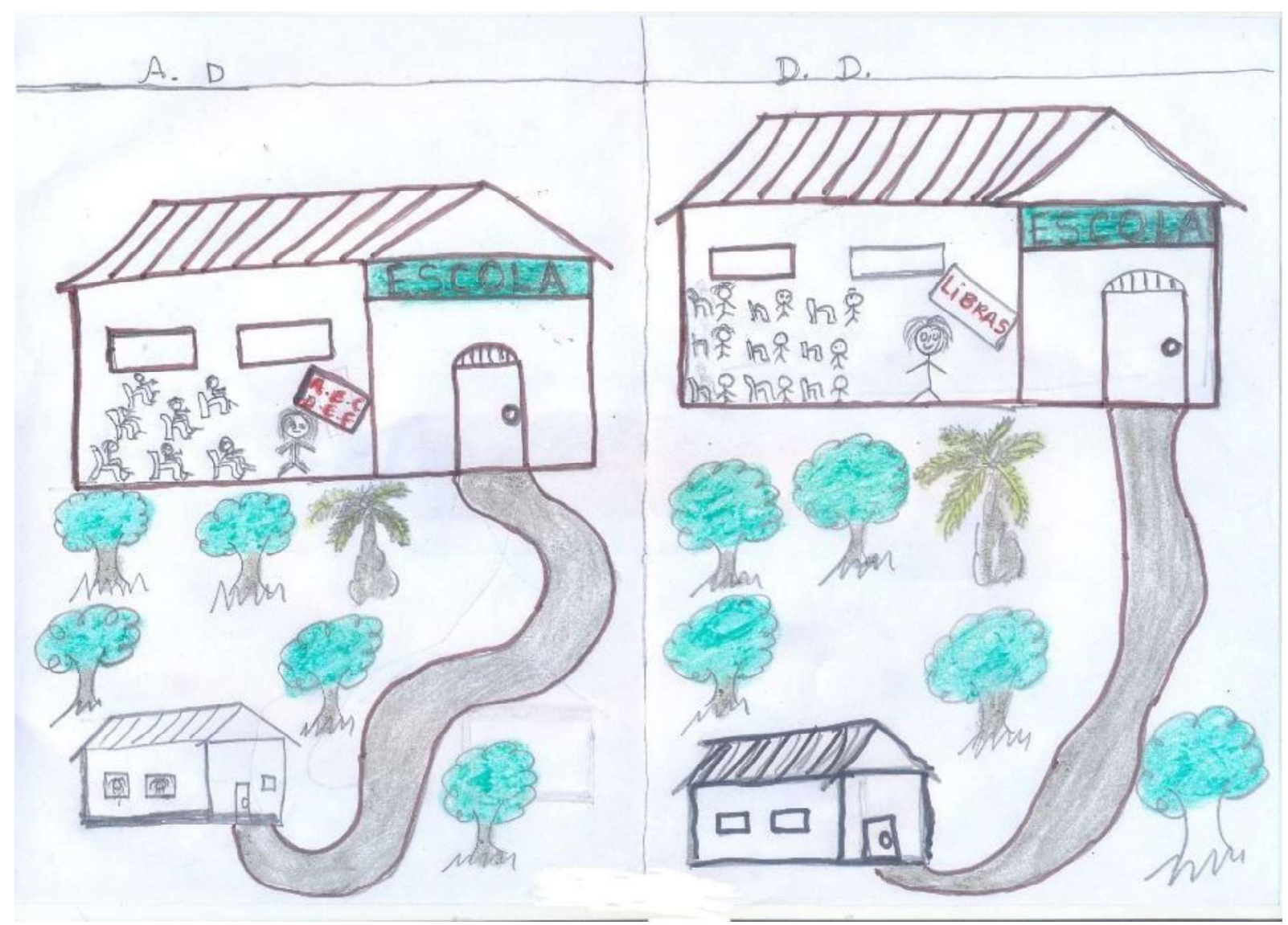

Fonte: $(\mathrm{G} 3,2018)$

Em seu desenho G3 reconhece a importância do uso da Libras em sala de aula como meio de comunicação e de inclusão, em que todos os integrantes da aula, professor e alunos ouvintes e surdos são participes do processo educacional.

Beyer (2006) explica que estar em um mesmo ambiente em que tenham pessoas deficientes e pessoas ditas normais não é descrito como inclusão, mas sim integração. Só podemos pensar em um ambiente inclusivo, quando ocorrem relações de comunicações diretas entre os sujeitos.

Assim, ilustra-se a necessidade de oportunizar um ambiente bilíngue que favoreça a interação entre surdos e ouvintes, pautado na diferença como selo da singularidade linguística, identitária e cultural de todos constituem e ocupam o espaço escolar.

O desenho da entrevistada G3 está na categoria da Dimensão Espacial, assim percebe-se que na sua RS há uma mudança na ação educativa acerca do aluno surdo. De acordo com Oliveira, Oliveira, Silveira (2018, p. 37) "a dimensão espacial pode representar a existência de mais de um lugar, com intuito do entrevistado comparar a relação de um com o outro". 


\subsection{DA NORMALIDADE PARA DIFERENÇA COMO ALTERIDADE: RESSIGNIFICAÇÕES DE RS DE GRADUANDOS DE LETRAS SOBRE O SURDO}

Como as Representações Sociais influenciam na marcação e na ação direta e indireta com o sujeito surdo? A partir dessa reflexão, pretende-se demarcar as falas dos graduandos antes e depois da disciplina ministrada.

Vale pontuar que as RS são base para a reflexão e ação sobre o objeto e o sujeito. Para tanto, Moscovici (2012) considera que, nas representações sociais, não existe uma linha que divide o universo exterior e o do indivíduo (ou grupo), que o sujeito e o objeto não são totalmente heterogêneos em seu campo comum. O objeto está inserido num contexto ativo, movediço, pois é, parcialmente, concebido pela pessoa ou pela coletividade como prolongamento de seu comportamento e, para eles, só existe como função dos meios e dos métodos que permitem conhecê-lo.

O autor ainda afirma que a representação social é a preparação para a ação, pois não só serve de guia para os comportamentos, mas também porque remodela e reconstitui, internamente, os elementos que circulam no ambiente, no qual o comportamento deve acontecer. Ela possibilita dar significados ao comportamento, integrá-lo numa rede de relações na qual está ligada ao objeto, viabilizando, ao mesmo tempo, noções as teorias e o fundo de observações que tornam essas relações possíveis e eficazes.

Com base nesta afirmação, infere-se que: dos 36 graduandos que participaram da pesquisa, todos demarcaram suas RS (prévia) sobre a pessoa surda no Campo da Normalidade e, com o término das aulas, 32 alunos ressignificaram para o Campo da Diferença como alteridade.

De acordo com Andrade-Silva (2014) a normalidade é:

Uma concepção de ser humano que ocorre quando se faz escolha de um modelo de corpo e de identidade ideais e requer que este seja arbitrariamente alcançados por todos os indivíduos, o que acarreta discriminação e preconceito de quem não se enquadra, de quem não está na imposição estabelecida como ideal (ANDRADE-SILVA, 2014, p. 67).

Com base nisso, a normalidade foi vista pelos sujeitos da pesquisa enquanto elemento justificativo para a criação de grupos normais (ouvintes) e anormais (surdos). O selo da diferença aqui descrito se fundamenta no: estigma, preconceito e na marginalização sobre o Outro/surdo, conforme descrito na tabela a seguir: 
Tabela 1: RS na Normalidade

\begin{tabular}{|c|c|c|c|}
\hline \multicolumn{5}{|c|}{ NORMALIDADE } \\
\hline Entrevistados & Para você quem é o surdo? & Ancoragem & Objetivação \\
\hline G1 & Aquele que não ouve. & Não ouvir. & $\begin{array}{c}\text { Porque falta um sentido biológico que } \\
\text { prejudica em tudo. }\end{array}$ \\
\hline G2 & O que não escuta e nem fala. & Não escutar. & $\begin{array}{c}\text { Porque ele não sabe ouvir e por isso } \\
\text { não sabe falar. }\end{array}$ \\
\hline G3 & $\begin{array}{c}\text { Aquele que apresenta ausência } \\
\text { dos sons. }\end{array}$ & $\begin{array}{c}\text { Ausência } \\
\text { dos sons. }\end{array}$ & $\begin{array}{c}\text { Não sabe identificar sons, porque não } \\
\text { escuta. }\end{array}$ \\
\hline
\end{tabular}

Fonte: Elaboração própria.

Os dados descritos na tabela anterior foram problematizados no decorrer de toda disciplina, haja vista que o ato de não ouvir foi ancorado enquanto limitação e se objetivou no prisma da ausência, da dificuldade e da normalidade. A normalidade, segundo Skliar (2006, p. 17) tem como propósito "em sua origem, a pretensão de ordenar a desordem originada pela perturbação dessa outra invenção, dessa outra fabricação, dessa outra produção que chamamos habitualmente de 'anormalidade".

Para a entrevistada G2, o surdo é surdo-mudo, em virtude de não ouvir e nem falar. Pesquisadores da área da Surdez ${ }^{4}$ ilustram que tal nomentaclutura foi descrita desde a Grécia antiga e é difundida até os dias atuais. Para tanto, tal marcação se situa no campo da normalidade. Vale pontuar que os surdos apresentam a mesma capacidade fonética de produzir sons com o aparelho fonador, porém precisam ser estimulados em tenra idade.

Corroborando com a RS marcada na Normalidade G1 e G3 inferem a pessoa surda na visão clínica/Patológica - aquele que não ouve - o que interfere em seu desenvolvimento psicológico, social, educacional e cultural. Assim, objetivam suas RS na ausência de um sentido (auditivo).

Jodelet (2001) define RS como uma forma de conhecimento, socialmente, elaborado e partilhado, que tem um objetivo prático e concorre para a estruturação de uma realidade comum a um conjunto social. E essas representações envolvem concepções historicamente construídas. Desta forma, o olhar da normalidade adquirida pelos sujeitos em práticas sociais cotidianas, com o término da disciplina foi substituída por outras RS, com base na compreensão da Diferença como alteridade, na qual o outro é visto como outro, em sua dimensão integral, como sujeito de capacidades, histórico, social e político.

Os entrevistados ao representarem o surdo nessa categoria configuram-se um olhar para o outro no campo da Alteridade. Falar de alteridade é falar de diferença, respeito, responsabilidade para com o outro, é perceber o "outro" por sua diferença e não como inferior (FREIRE, 2004). 
Compreende-se o conceito da alteridade quando "o ser capaz de apreender o outro na plenitude da sua dignidade, dos seus direitos e, sobretudo, da sua diferença. Quanto menos alteridade existe nas relações pessoais e sociais, mais conflitos ocorrem". (BETTO, 2000, p. 7)

Ao destacar as RS sobre a pessoa surda no campo da diferença linguística foram expressas nas falas dos sujeitos alguns aspectos da singularidade do sujeito surdo: visuais; bilíngues e usuários da língua de sinais, conforme a tabela 2 a seguir.

Tabela 2: RS na Diferença como Alteridade.

\begin{tabular}{|c|l|l|l|}
\hline \multicolumn{4}{|c|}{ DIFERENÇA COMO ALTERIDADE } \\
\hline Entrevistados & Para você quem é o surdo? & Ancoragem & \multicolumn{1}{c|}{ Objetivação } \\
\hline G1 & $\begin{array}{l}\text { Aquele que tem uma língua } \\
-\quad \text { Língua Brasileira de } \\
\text { Sinais. }\end{array}$ & $\begin{array}{l}\text { Língua } \\
\text { Própria. }\end{array}$ & $\begin{array}{l}\text { O surdo é o usuário da Libras que é uma } \\
\text { língua reconhecida pela Lei de 2002. }\end{array}$ \\
\hline G2 & É um sujeito visual. & LIBRAS. & Característica da Língua - visuo-espacial. \\
\hline G3 & É uma bilíngue. & Bilíngue. & $\begin{array}{l}\text { Bilíngue, pois sabe a Língua de Sinais } \\
\text { (LIBRAS) e sabe o português. }\end{array}$ \\
\hline
\end{tabular}

Fonte: Elaboração própria.

A compreensão dos sujeitos da diferença como alteridade oportuniza a reavaliação e problematização de RS normalizadoras e possibilita a ressignificação de si diante do outro, a percepção do outro e a modificação de RS negativas acerca do educando surdo. Desse modo, G1 ao mencionar que o surdo é usuário da Libras faz uma marcação na potencialidade do sujeito e não na ausência. A Libras é uma língua "reconhecida como meio legal de comunicação e expressão" (BRASIL, 2002). A Língua Brasileira de Sinais - LIBRAS é entendida como:

Parágrafo Único - [...] forma de comunicação e expressão, em que o sistema linguístico de natureza visual-motora, com estrutura gramatical própria, constituem um sistema linguístico de transmissão de ideias e fatos, oriundos de comunidades de pessoas surdas do Brasil (BRASIL, 2002, p. 1).

G1 ilustra a língua do surdo como elemento formativo de sua identidade, ação esta já descrita por Lopes (2007). A marca da diferença como alteridade, que considera o "outro" como diferente não como oposto ao "normal", mas como é, em seu modo mais singular, é reconhecê-lo a partir da consciência de sua diferença (SKLIAR, 2006). A partir desse pensamento, ilustra-se que a Língua Brasileira de Sinais - Libras - é elemento imprescindível na constituição do sujeito surdo.

G2 ao dizer que "o sujeito surdo é um ser visual", compreende o visual como uma das especificidades do surdo, no sentido de que: "[ter] experiência visual significa a utilização da visão, (em substituição total a audição), como meio de comunicação" (PERLIN; MIRANDA, 2003, p. 218). Mas isto não significa que a pessoa surda não utiliza os seus demais sentidos no processo de conhecer o mundo.

A ancoragem presente na fala de G2 revela a visão do surdo como elemento formativo identitário e educacional. A RS de G3 considera o sujeito surdo como um ser bilíngue e que deve 
ter uma educação bilíngue. Uma educação bilíngue defende que a pessoa surda seja educada, conjuntamente, com a Língua de Sinais e a Língua Portuguesa (modalidade escrita). Nessa perspectiva, o Bilinguismo:

[...] contrapõe-se ao modelo oralista porque considera o canal viso gestual de fundamental importância para a aquisição de linguagem da pessoa surda. E contrapõe-se à comunicação total porque defende um espaço efetivo para a língua de sinais no trabalho educacional; por isso advoga que cada uma das línguas apresentadas ao surdo mantenha suas características próprias e que não se 'misture' uma com a outra (LACERDA, 1998 p. 10).

Utilizar a Língua de Sinais para se comunicar é, também, uma forma de afirmação de identidade surda. A partir da metodologia Bilíngue, o surdo deixa de tentar seguir o processo de aquisição de conhecimento do ouvinte e passa a desenvolver sua identidade no contato com seus pares, com os alunos ouvintes, com o intérprete educacional e com os professores.

Este estudo evidenciou que as RS de G1, G2 e G3 foram ressignificadas do campo da Normalidade para Diferença como Alteridade ilustrando-se que "Ser surdo é viver permanentemente reivindicando um outro olhar do outro sobre si e viver permanentemente suspeitando do seu própria olhar sobre si mesmo". (LOPES, 2007, p. 56).

Assim, o sujeito surdo deve ser visto enquanto um grupo político, identitário e linguístico presente na sociedade. Tal visão não anula o campo clínico/patológico, todavia, enfatiza que:

Não há uma forma única de ser surdo e não há uma essência acima de qualquer atravessamento cultural; há, sim, representações, códigos, sentimentos compartilhados por um grupo de pessoas, todos forjados nas experiências vivenciadas por sujeitos surdos diferentes e em espaços distintos (LOPES, 2007, p. 88).

As RS dos entrevistados, então, superaram a representação de normalidade e firmaram-se no princípio da Alteridade, ao reconhecerem o surdo a partir do que é, bem como ao compreenderem que os entrevistados idealizam uma prática educativa de convivência direcionada para as diferenças socioculturais e individuais do sujeito surdo. (OLIVEIRA, 2015)

\section{CONSIDERAÇÕES FINAIS}

O estudo teve como objetivo investigar as RS de graduandos do curso de Letras- Língua Portuguesa do Parfor/UFPA sobre a pessoa com Surdez e de forma específica: analisar as imagens e os sentidos atribuídos pelos graduandos de Letras - Língua Portuguesa sobre a pessoa surda antes e depois da disciplina de Libras e elucidar as RS sobre a Surdez, no âmbito da Normalidade e Diferença como alteridade.

Observamos que os sujeitos pesquisados possuíam uma RS acerca da Surdez no campo da Normalidade e que foram superadas e ressignificadas para a Diferença como Alteridade. 
Este estudo oportuniza a reflexão sobre a importância da inserção da disciplina Libras nos cursos de graduação, em especial, nos cursos de licenciatura, visto que o futuro professor irá se deparar, tão logo, com aluno (s) surdo (s) em sua sala de aula. Também, há de ser destacar a questão do conhecimento do ensino de Libras como conhecimento científico-prático na graduação, conhecimento que fornecerá subsídios (mesmo que gerais ou superficiais) para o futuro professor atuar em sua prática pedagógica.

O ensino de Libras proporciona ao estudante (ouvinte) o contato com concepções diferenciadas sobre as pessoas surdas, assim como o contato com as especificidades de sua vida cotidiana e ao processo de comunicação por meio da Libras, possibilitando-lhe ressignificar suas representações acerca da Surdez e contribuir para mudanças atitudinais e comunicacionais com o educando surdo, favorecendo o processo de inclusão escolar.

\footnotetext{
Nascimento (2013, p. 52) explica que ancoragem é atribuição pela sociedade de uma escala de valores e preferências para um objeto social em função das interações sociais. Em outras palavras, o processo de ancoragem delimita o campo de uma representação, e permitem que esta delimitação seja compatível com os valores sociais existentes. Pode ser entendido como um processo de interiorização ou apropriação de uma estrutura simbólica cujos filtros são valores sociais.

${ }^{2}$ Nascimento (2013, p. 50) narra que a "objetivação pode-se ser vista nesse processo de formação das representações sociais como um recurso que o pensamento utiliza, denominado de naturalização, para tornar concretos, reais, conceitos abstratos".

${ }^{3}$ Por barreiras comunicacionais entende-se "[...] qualquer entrave ou obstáculo que dificulte ou impossibilite a expressão ou o recebimento de mensagens por intermédio dos meios ou sistemas de comunicação, sejam ou não de massa" (BRASIL, 2000).

${ }^{4}$ Lacerda (2009), Skliar (1998), Oliveira (2015).
}

\section{REFERÊNCIAS}

ALVEZ-MAZZOTTI, A. J; MAGALHÃES, E. M. M; MAIA, H. Representações sociais de trabalho docente: significados atribuídos a dedicação por professores das séries iniciais e seus formadores. Disponível: $<$ http://www.estudosdotrabalho.org/anais-vii-7-seminario-trabalhoret2010>. Acesso em: 10. 04. 2010.

ANDRADE-SILVA, C. F. C. Representações Sociais de discentes do Curso de Letras-Libras da UEPA acerca da pessoa surda. 2014, 130 f. Dissertação (Mestrado em Educação). Universidade do Estado do Pará. Belém, 2014.

BARDIN, L. Análise de conteúdo. Lisboa, Portugal: Edições 70, 2010.

BETTO, F. Reflexão Pós - Modernidade e novos paradigmas. Instituto Ethos. Ano I - $\mathrm{n}^{\mathrm{o}} 3$, novembro de 2000.

BRASIL. Decreto Lei $n .10436$ de 24 de abril de 2002. Dispõe sobre a língua de Sinais e outras providências. Disponível em: www.planalto.gov.br/ccivil_03/Leis/2002/L10436.htm>. Acesso em: 28 fev. 2018. 
BRASIL. Decreto n. 5.626 de 22 de dezembro de 2005. Regulamenta a Lei n. 10.436, de 24 de abril de 2002, que dispõe sobre a Língua Brasileira de Sinais - Libras. Disponível em: $<$ www.planalto.gov.br/ccivil_03/_ato2004.../2005/decreto/d5626.htm>. Acesso em: 28 fev. 2018.

BRASIL. Diretrizes e Bases da Educação Nacional - Lei 9.394. Brasília. DF: Senado Federal, 1996. Disponível em: <http://www.planalto.gov.br/ccivil_03/LEIS/L9394.htm>Acesso em: 28 fev. 2018.

BRASI. Lei $N^{o}$ 10.098, promulgada em 19 de dezembro de 2000. Estabelece normas gerais e critérios básicos para a promoção da acessibilidade das pessoas portadoras de deficiência ou com mobilidade reduzida, e dá outras providências. Diário Oficial da União: República Federativa do Brasil, Brasília, DF, 20 dezembro 2000. Disponível em: $<$ http://www.planalto.gov.br/ccivil_03/leis/L10098.htm>. Acesso em: 28 fev. 2018.

CHIZZOTTI, A. Pesquisa em ciências humanas e sociais. 10. ed. São Paulo: Cortez, 2009

DOZIART, A. O outro da educação: pensando a surdez com base nos temas Identidades/Diferença, Currículo e Inclusão. Vozes: Petrópolis-RJ, 2009.

FREIRE, P. Pedagogia da Autonomia: saberes necessários à prática educativa. São Paulo: Paz e Terra, 1999.

FREIRE, P. Pedagogia do Oprimido. 38 ed. Rio de Janeiro: Paz e Terra, 2004.

GAMBOA, S. S. SANTOS FILHO, J. C. Pesquisa Educacional: quantidade-qualidade, 1 ed. São Paulo: Cortez, 1994.

GOLDFELD, M. $\boldsymbol{A}$ criança surda: linguagem e cognição numa perspectiva sóciointeracionista. São Paulo: Plexus, 1997.

LACERDA, C. B. O intérprete de língua de sinais no contexto de uma sala de aula ouvintes: problematizando a questão. In: LACERDA, C. B. ; GÓES, M. C. R. (Org.). Surdez: processos educativos e subjetividade. São Paulo: Lovise, 2000, p. 51-84.

LACERDA, C. B. Um pouco da história das diferentes abordagens na educação de surdos. Caderno cedes, vol. 19, n 46. Campinas, 1998.

LIMA, N. M. F. Inclusão escolar de surdos: o dito e feito. In: DORZIAT, A. Estudos surdos diferentes olhares. Porto Alegre: Mediação, 2011, p.141- 170.

LODI, A. B. O intérprete de Língua Brasileira de Sinais/Língua Portuguesa e sua prática em diferentes espaços sociais. Anais do VI Congresso IBERO-AMERICANO de Tradução $e$ Interpretação. São Paulo: Unibero CD Rom, 2006.

LOPES, M. C. Surdez e Educação. Belo horizonte: editora Autêntica, 2007.

LUDKE, M.; ANDRÉ, M. Pesquisa em educação: abordagens qualitativas, SP EPUD, 1986.

MINAYO, M. C. S. Trabalho de campo: contexto de observação, interação e descoberta. DESLANDES, S. F; GOMES, R; MINAYO, M. C. S. (Org.). In: Pesquisa social: teoria, método e criatividade. 29 ed. Petrópolis, RJ: Vozes, 2010. p.61-77. 
MOSCIVICI, S. A representação social da psicanálise. Rio de Janeiro: Zahar, 1981.

MOSCIVICI, S. Representações sociais: investigações em psicologia social. 5 ed. Petrópolis-RJ: Vozes, 2009.

NASCIMENTO, I. P. Articulações sobre o campo das representações sociais. In: ORNELLAS, M. L. S. Representações Sociais e educação: letras imagéticas. Salvador: EDUFBA, 2013.

OLIVEIRA, W. M. M. Representações Sociais de educandos surdos sobre a atuação do Intérprete Educacional no Ensino Superior. 2015, 236 f. Dissertação, (Mestrado em Educação). Universidade do Estado do Pará, Belém, 2015.

OliveirA, I. A; OliveirA, W. M. M. O; SIlVEIRA, A. P. A Técnica do Desenho na Pesquisa Educacional sobre Representações Sociais. In: OLIVEIRA, I. A; OLIVEIRA, W. M. M; LOBATO, H. K. G. Pesquisa Educacional sobre Representações Sociais o uso da técnica do desenho e dos mapas conceituais. São Carlos: Pedro \& João Editores, 2018, p. 21 - 54.

ORNELLAS, M. L. S. Representação Social: um conceito estiloso - escapa e reencontra. In: ORNELLAS, M. L. S. Representações Sociais e educação: letras imagéticas. Salvador: EDUFBA, 2013, 21-34.

PERLIN G; MIRANDA, W. Surdos: o Narrar e a Política. Estudos Surdos - Ponto de Vista: Revista de Educação e Processos Inclusivos, nº 5, UFSC/ NUP/CED, Florianópolis, 2003.

QUADROS, R. M. O 'BI’ em bilinguismo na educação de surdos. In: FERNANDES, E. (Orgs.). Surdez e bilinguismo. Porto Alegre: Mediação, 2005.

RANGEL, M. A pesquisa de Representação Social como forma de enfrentamento de problemas socioeducacionais. Aparecida São Paulo: Ideias e Letras, 2004.

SÁ, C. P. Representações sociais: o conceito e o estado atual da teoria. In: SPINK, M. J. P. $O$ conhecimento no cotidiano: as representações sociais na perspectiva da psicologia social. São Paulo: Brasiliense, 2004, p.19-45.

SANTOS, L. F.; CAMPOS, M. L. I. L. O ensino de Libras para futuros professores da educação básica. In: LACERDA, C. B. F; SANTOS, L.F. Tenho um aluno surdo, e agora? EdUfscar, 2013. P.237-250

SILVEIRA, A. P. Representações Sociais de professores do Ensino Fundamental sobre o aluno surdo: A [in] visibilidade na inclusão escolar. 2011. Dissertação (Mestrado em Educação). Universidade do Estado do Pará, Belém. Disponível em: www.page.uepa.br/mestradoeducacao Acesso em: 04 maio 2018.

SKLIAR, C. A inclusão que é "nossa e a diferença que é do "outro". In: RODRIGUES, D. Inclusão e educação: doze olhares sobre educação inclusiva. São Paulo: Summus, 2006, p. 16-34.

SKLIAR, C. Os estudos surdos em educação: problematizando a normalidade. In: SKLIAR, C. (Org.). A surdez: um olhar sobre a diferença. Porto alegre, Mediação, 1998, p.07-32.

SKLIAR, C. Uma perspectiva sócio-histórica sobre a psicologia e a educação dos surdos. In: SKLIAR, C. (Org.). Educação \& exclusão abordagens socioantropológicas em educação especial. Porto Alegre: Mediação, 6 ed. 2010, p. 73-111. 
SKLIAR, C. (Org.) Educação \& Exclusão: abordagens sócio-antropologicas em educação especial. Porto Alegre: Mediação,1997.

SOUZA, R. R. Representações sociais de professores sobre a inclusão escolar de alunos com necessidades especiais. 2009. Dissertação (Mestrado em Educação) - Universidade do Estado do Pará. Disponível em: <www.page.uepa.br/mestradoeducacao> Acesso em: 04 nov. 2013.

VÍCTORA, C. G. et al. Pesquisa qualitativa em saúde: uma introdução ao tema. Porto Alegre: Tomo Editorial, 2000.

Recebido em 22.02.2019

Aprovado em 06.03.2019 